\title{
Hepatitis E virus infection in swine workers: A meta-analysis
}

\author{
Xiangyuan Huang $^{1}$ | Yu Huang ${ }^{1}$ | Abram L. Wagner ${ }^{2}$ | Xiangxiang Chen ${ }^{1}$ | \\ Yihan $\mathrm{Lu}^{1,3}$
}

\author{
${ }^{1}$ Department of Epidemiology, Fudan \\ University School of Public Health, Key \\ Laboratory of Public Health Safety (Ministry \\ of Education), Shanghai, China \\ ${ }^{2}$ Department of Epidemiology, University of \\ Michigan, Ann Arbor, Michigan \\ ${ }^{3}$ Fudan University Pudong Institute of \\ Preventive Medicine, Shanghai, China
}

\section{Correspondence}

Yihan Lu, Department of Epidemiology, Fudan University School of Public Health, Key Laboratory of Public Health Safety (Ministry of Education), Shanghai, China.

Email: luyihan@fudan.edu.cn

Funding information

the Fulbright Scholarship; the China National Natural Science Funds, Grant/Award

Number: 81370081; Shanghai Municipal Health and Family Planning Commission, Grant/Award Number: GWTD2015S05

\begin{abstract}
Hepatitis E virus (HEV) infects both humans and animals. Swine has been confirmed to be the principal natural reservoir, which raises a concern that HEV infection would be substantially increasing among swine workers. The present study calculated the pooled prevalence of IgG antibodies against HEV among swine workers and the general population in previous cross-sectional studies. We conducted a meta-analysis comparing the prevalence of HEV infection between swine workers and the general population, including local residents, blood donors and non-swine workers. Through searches in three databases (PubMed and OVID in English, and CNKI in Chinese) and after study selection, a total of 32 studies from 16 countries (from 1999 through 2018) were included in the meta-analysis. A random-effect model was employed in the study; an I $^{2}$ statistic assessed heterogeneity, and the Egger's test detected publication bias. The comparative prevalence of anti-HEV IgG was pooled from the studies. Compared to the general population, the prevalence ratio (PR) for swine workers was estimated to be 1.52 (95\% Cl 1.38-1.76) with the $I^{2}$ being $71 \%$. No publication bias was detected $(p=0.40)$. A subgroup analysis further indicated increased prevalence of anti-HEV IgG in the swine workers in Asia ( $P R=1.49,95 \% \mathrm{Cl}: 1.35-1.64)$, in Europe ( $P R=1.93,95 \% \mathrm{Cl}: 1.49-2.50)$ and in all five swine-related occupations, including swine farmers, butchers, meat processors, pork retailers and veterinarians (PR ranged between 1.19 and 1.75). In summary, swine workers have a relatively higher prevalence of past HEV infection, and this finding is true across swine-related occupations, which confirms zoonotic transmission between swine and swine workers.
\end{abstract}

\section{KEYWORDS}

Hepatitis E virus, meta-analysis, swine worker, zoonosis

\section{1 | INTRODUCTION}

Hepatitis E virus (HEV) is a single-strand positive RNA virus that causes hepatitis E. HEV genome consists of $7.2 \mathrm{~kb}$, with 3 or 4 overlapping open reading frames (ORFs) (Mushahwar, 2008; Nair et al., 2016). So far, HEV has been classified into seven genotypes (Smith et al., 2014). Genotypes 1 and 2 infect only humans, whereas other genotypes infect diverse species including humans (genotype 3, 4 and 7), swine (genotype 3 and 4), wild boar (genotype 3-6), rabbits (genotype 3), deer (genotype 3), mongooses (genotype 3), yaks (genotype 4) and camels (genotype 7; Nan \& Zhang, 2016). Swine has been confirmed to be a principal reservoir based on evidence from both epidemiological observations and experimental studies. The prevalence of antibodies against HEV (anti-HEV) has been reported to range between $8 \%$ and $93 \%$ among swine across the world which is much higher than other animal reservoirs, with variation 
in different swine herds and countries (Salines, Andraud, \& Rose, 2017). Additionally, a phylogenetic analysis has demonstrated that human and swine HEV strains isolated from the same regions share high sequence identities of up to $91.3 \%-100 \%$, suggesting a close phylogenetic relationship (Liu et al., 2012). Experimental cross-species transmission of HEV has also been confirmed across humans, non-human primates and swine with genotypes 3 and 4 (Doceul, Bagdassarian, Demange, \& Pavio, 2016).

Swine workers, including swine farmers, butchers, meat processors, pork retailers and veterinarians are routinely exposed to swine and are consequently at possible risk of HEV infection. It has been documented that the prevalence of anti-HEV IgG in swine workers ranged between 3.3\% (swine farmers, Italy) and 75.9\% (swine farmers, China), which is higher than that in the general population in the same regions (De Schryver et al., 2015). However, some studies have reported a similar prevalence of HEV between swine workers and the general population, such as in one study in Thailand (Hinjoy et al., 2013). Additionally, it remains unclear which occupation is more likely to be infected with HEV. A study of anti-HEV IgG prevalence in occupations including butcher, meat processor, swine farmer and veterinarian reported relatively higher anti-HEV IgG in butchers and meat processors, but differences were not significant (Yan et al., 2007).

Because there are conflicting findings of increased prevalence of HEV infection in swine workers relative to the general population, this study combined previous findings in a meta-analysis. This study calculated the prevalence of HEV infection in swine workers compared to the general population, and further determined possible regions and occupations associated with increased prevalence of HEV infection.

\section{2 | MATERIALS AND METHODS}

\section{1 | Data sources}

Two international databases, PubMed and OVID, and one Chinese database, CNKI, were searched for studies focusing on HEV infection among swine workers from their inception to April 2017. The data were subsequently updated until April 2018 by using the same strategy. The search terms "Hepatitis E Virus" and "swine" were used as shown in Table 1. Two independent investigators conducted the search and then determined whether a study was potentially related to our study objective according to its title and abstract. Studies

\section{Impacts}

- Hepatitis E virus is a zoonotic virus that has been widespread in low-, middle- and high-income countries. Swine has been confirmed to be the principal natural reservoir.

- The pooled prevalence of anti-HEV IgG has been estimated to be significantly higher in swine workers than in the general population, especially in Asia and Europe, regardless of socioeconomic circumstances of country.

- We demonstrate that the prevalence of anti-HEV IgG increased across five swine-related occupations, including swine farmers, butchers, meat processors, pork retailers and veterinarians, suggesting substantial risk of cross-species transmission.

that were considered acceptable by either investigator were added to NoteExpress version 3.2 (Aegean Technology Co. Ltd., Beijing, China) for further selection.

\section{2 | Study selection}

The full text of the retrieved studies was reviewed for selection. The inclusion criteria were as follows: (a) the study was cross-sectional; (b) the study included both swine workers and the general population in the same region; and (c) anti-HEV IgG was examined and reported. The exclusion criteria were as follows: (a) the study was a conference article or abstract; (b) the study repeated findings from a previous study; or (c) the study was about wild boars. The two investigators independently carried out the selection. Conflicting decisions were addressed by negotiation or further judged by a third investigator.

\subsection{Data extraction}

The selected studies were read for data extraction. The data of interest included author, year of publication, sampling site, country or region of sampling, time of sampling, definition of occupation and general population, sample size of both swine workers and general population, number of HEV infections in both swine workers and

TABLE 1 Search strategies and results

\begin{tabular}{|c|c|c|c|c|}
\hline Database & Strategy & No. of publications & Date of search & $\begin{array}{l}\text { Date of } \\
\text { updated search }\end{array}$ \\
\hline PUBMED & $\begin{array}{l}\text { (HEPATITIS E VIRUS[Title/Abstract]) AND (SWINE[Text } \\
\text { Word] OR PIG[Text Word] OR PORCINE[Text Word] } \\
\text { OR HOG[Text Word]) }\end{array}$ & 698 & 2017.4 .8 & 2018.4.30 \\
\hline CNKI & ( TI= “戊型肝炎”OR TI= “戊肝”) AND (FT= “猪”) & 528 & 2017.4 .8 & 2018.4.30 \\
\hline OVID & $\begin{array}{l}\text { hepatitis e virus.kw,ti,ab. and (swine or porcine or pig or } \\
\text { hog).tw. }\end{array}$ & 761 & 2017.4 .10 & 2018.4.30 \\
\hline
\end{tabular}




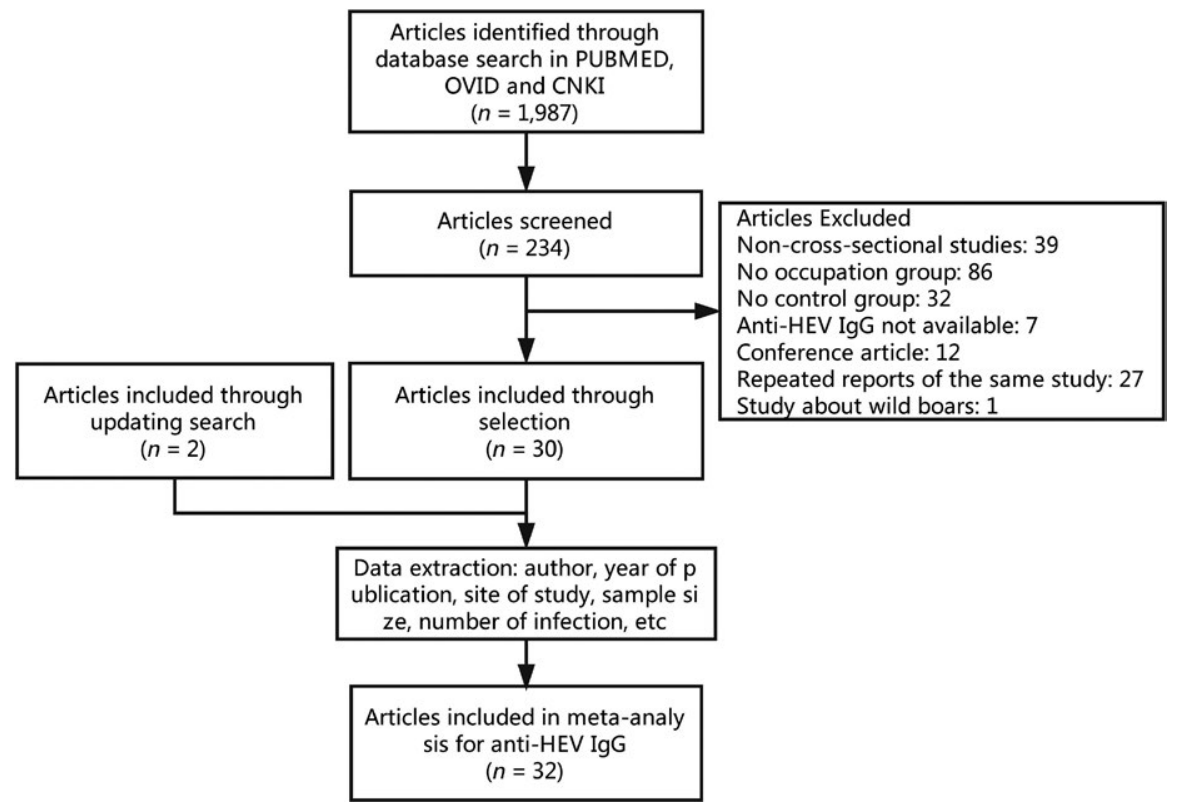

FIGURE 1 Flow chart of the meta-analysis

the general population, and laboratory examination methods. These data were retrieved by one investigator and then confirmed by another investigator. For studies that only provided sample size and prevalence of HEV infection, we calculated the number of infections.

\section{4 | Statistical analysis}

The meta-analysis was conducted with $R$ software version 3.4 ( $R$ Development Core Team, Vienna, Austria) and the package meta version 4.8 (Guido Schwarzer, Baden-Württemberg, Germany). To pool the comparison of HEV infection in swine workers and the general population, the prevalence ratio (PR) was estimated across the included studies with a random effect. An $I^{2}$ statistic was calculated to assess heterogeneity across studies, with an $I^{2}>50 \%$ considered to be high heterogeneity. Egger's test was used to detect potential publication bias. Additionally, a subgroup analysis was conducted by stratifying by continent of study and occupation.

\section{3 | RESULTS}

\section{1 | Data retrieval and study selection}

As shown in Figure 1, a total of 1987 studies were initially found in CNKI, PubMed and OVID, in which 234 studies were potentially related to our study objectives and had a full text retrieved. Subsequently, 204 studies were excluded with reasons listed in Figure 1, and two studies were added in an updated search, yielding 32 studies for the meta-analysis (Bouwknegt et al., 2008; Caruso et al., 2017; De Sabato et al., 2017; Drobeniuc et al., 2001; Engle, Yu, Emerson, Meng, \& Purcell, 2002; Galiana, Fernandez-Barredo, Garcia, Gomez, \& Perez-Gracia, 2008; Hinjoy et al., 2013; Hongwei, 2009;
Jiang, Zheng, \& Shijuan, 2009; Kang et al., 2017; Krumbholz et al., 2014, 2012; Lange et al., 2017; Lee et al., 2013; Liang et al., 2014; Liu et al., 2007; Love, Bjornsdottir, Olafsson, \& Bjornsson, 2018; Lu et al., 2006; Masia et al., 2009; Meng et al., 1999, 2002; Nong, Li, \& Yi, 2007; Olsen, Axelsson-Olsson, Thelin, \& Weiland, 2006; Silva et al., 2012; Traore et al., 2015; Utsumi et al., 2011; Vivek \& Kang, 2011; Wu, Liao, Wang, Lou, \& Wenzhong, 2018; Wu, Xie, et al., 2016; Yan et al., 2007; Yu et al., 2009; Zheng et al., 2006). Of the included studies, 24 were published in English and eight in Chinese. The year of publication ranged from 1999 through 2018, and the majority of studies were conducted in either Asia $(n=17)$ or Europe $(n=11)$. In the studies, the swine workers included swine farmers, butchers, meat processors, pork retailers and veterinarians, whereas the general population included local residents and blood donors. Characteristics of the included studies are shown in the Supporting Information Table S1.

\section{2 | Meta-analysis}

By combining 32 studies with a random effect (Figure 2), the pooled prevalence of anti-HEV IgG was determined to be significantly higher in the swine workers (32.85\%) than in the general population (21.70\%), with a corresponding PR of 1.52 (95\% Cl: 1.38-1.76; Table 2). However, the heterogeneity was high, as indicated by the $I^{2}$ being $71 \%$. Publication bias was not indicated through Egger's test $(p=0.40)$.

The included studies that reported prevalence of anti-HEV IgG were conducted in different continents, including Asia $(n=17)$, Europe $(n=11)$, Africa $(n=1)$, North America $(n=2)$ and South America $(n=1)$. According to a subgroup analysis stratified by continent (Figure 3 and Table 2), the difference in the pooled prevalence of anti-HEV IgG between swine workers and the general population 


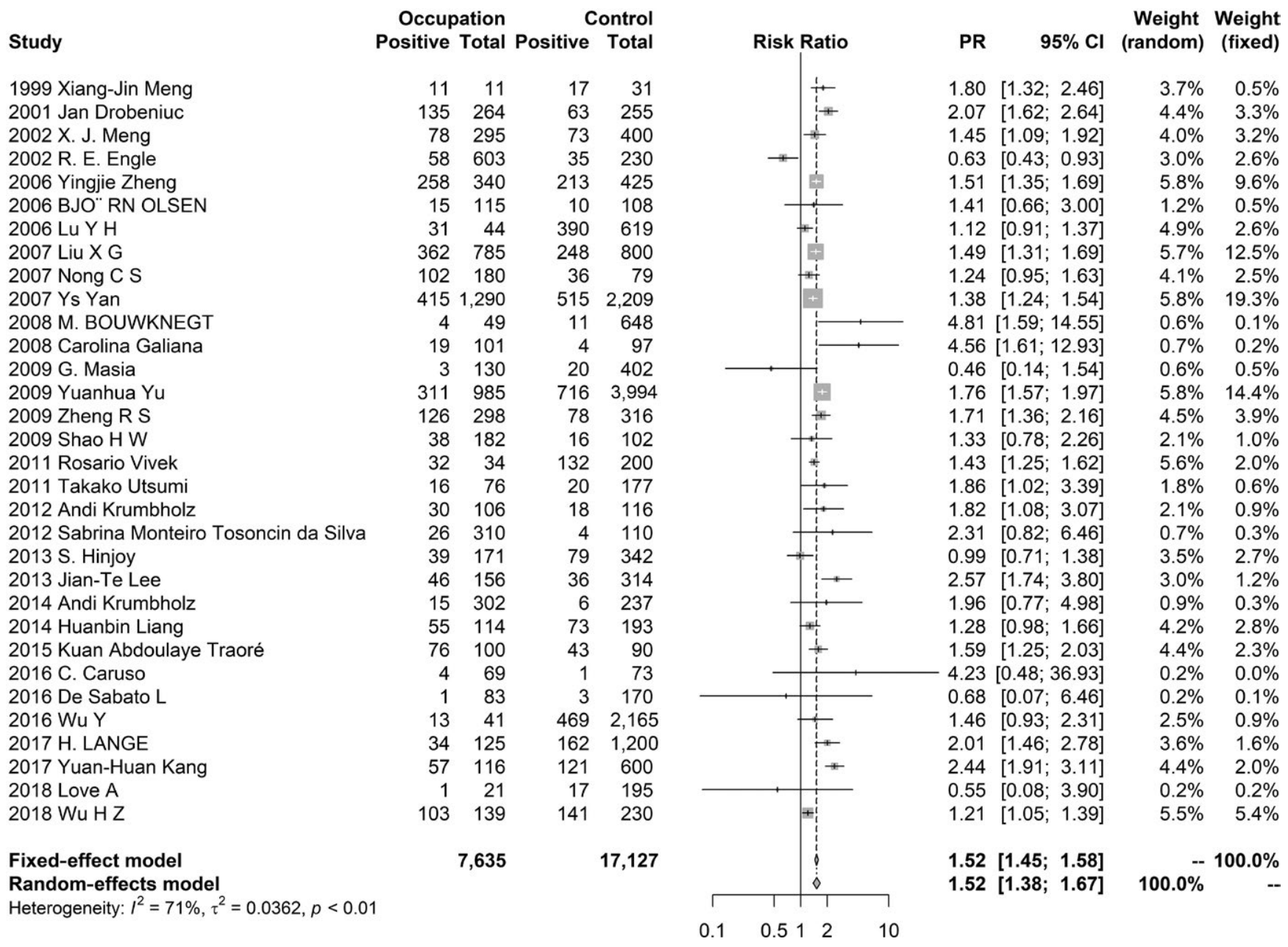

FIGURE 2 Overall analysis of anti-HEV IgG prevalence

\begin{tabular}{|lllll|}
\hline Model & No. studies & PR & $95 \% \mathrm{Cl}$ & $I^{2}$ \\
\hline Overall IgG & 32 & 1.52 & $1.38-1.67$ & $71 \%$ \\
\hline Subgroup by continent & & & & \\
\hline Africa & 1 & 1.59 & $1.25-2.03$ & Not applicable \\
\hline Asia & 17 & 1.49 & $1.35-1.64$ & $74 \%$ \\
\hline Europe & 11 & 1.93 & $1.49-2.50$ & $32 \%$ \\
\hline North America & 2 & 0.97 & $0.43-2.18$ & $91 \%$ \\
\hline South America & 1 & 2.31 & $0.82-6.46$ & Not applicable \\
\hline Subgroup by occupation & & & & \\
\hline Swine farmers & 26 & 1.51 & $1.32-1.74$ & $81 \%$ \\
\hline Butchers & 5 & 1.75 & $1.31-2.35$ & $86 \%$ \\
\hline Meat processors & 1 & 1.46 & $1.13-1.89$ & Not applicable \\
\hline Pork retailers & 2 & 1.19 & $1.09-1.29$ & $0 \%$ \\
\hline Veterinarians & 6 & 1.36 & $1.15-1.61$ & $14 \%$ \\
\hline
\end{tabular}

TABLE 2 Overall and subgroup analysis of anti-HEV IgG with random effects remained significant in Asia ( $P R=1.49,95 \% \mathrm{Cl}: 1.35-1.64)$ and Europe $(P R=1.93,95 \% \mathrm{Cl}: 1.49-2.50)$, whereas it was not significant in North America ( $P R=0.97,95 \% \mathrm{Cl}$ : 0.43-2.18). Because only one study was conducted in Africa and South America, estimates for these continents may be not generalizable. Additionally, heterogeneity was low $\left(l^{2}=32 \%\right)$ in Europe, whereas it was high in other subgroups $\left(I^{2} \geq 74 \%\right)$.

In our study, swine workers could be a part of any swine-related occupation. In the included studies, some contained more than one occupation. According to a subgroup analysis stratified 
Study

Occupation Contro

Positive Total Positive Total

continent $=$ africa

2015 Kuan Abdoulaye Traoré

Fixed-effect model

Random-effects model

Heterogeneity: not applicable

continent $=$ asia

1999 Xiang-Jin Meng

2006 Yingjie Zheng

2006 Lu Y H

2007 Liu X G

2007 Nong C S

2007 Ys Yan

2009 Yuanhua Yu

2009 Zheng R S

2009 Shao H W

2011 Rosario Vivek

2011 Takako Utsumi

2013 S. Hinjoy

2013 Jian-Te Lee

2014 Huanbin Liang

$2016 \mathrm{Wu}$ Y

2017 Yuan-Huan Kang

$2018 \mathrm{Wu} \mathrm{H} \mathrm{Z}$

Fixed-effect model

Random-effects model

Heterogeneity: $I^{2}=74 \%, \tau^{2}=0.0255, p<0.01$

continent $=$ europe

2001 Jan Drobeniuc

2006 BJO" RN OLSEN

2008 M. BOUWKNEGT

2008 Carolina Galiana

2009 G. Masia

2012 Andi Krumbholz

2014 Andi Krumbholz

2016 C. Caruso

2016 De Sabato L

$2017 \mathrm{H}$. LANGE

2018 Love A

Fixed-effect model

Random-effects mode

Heterogeneity: $I^{2}=32 \%, \tau^{2}=0.0482, p=0.14$

continent $=$ north america

2002 X. J. Meng

2002 R. E. Engle

Fixed-effect model

Random-effects mode

Heterogeneity: $I^{2}=91 \%, \tau^{2}=0.3140, p<0.01$

continent $=$ south america

2012 Sabrina Monteiro Tosoncin da Silva

Fixed-effect model

Random-effects mode

Heterogeneity: not applicable

Fixed-effect model

Random-effects model

Heterogeneity: $I^{2}=71 \%, \tau^{2}=0.0362, p<0.01$ $\begin{array}{rrrr}76 & 100 & 43 & 90 \\ & 100 & & 90\end{array}$

$\begin{array}{rrrr}11 & 11 & 17 & 31 \\ 258 & 340 & 213 & 425 \\ 31 & 44 & 390 & 619 \\ 362 & 785 & 248 & 800 \\ 102 & 180 & 36 & 79 \\ 415 & 1,290 & 515 & 2,209 \\ 311 & 985 & 716 & 3,994 \\ 126 & 298 & 78 & 316 \\ 38 & 182 & 16 & 102 \\ 32 & 34 & 132 & 200 \\ 16 & 76 & 20 & 177 \\ 39 & 171 & 79 & 342 \\ 46 & 156 & 36 & 314 \\ 55 & 114 & 73 & 193 \\ 13 & 41 & 469 & 2,165 \\ 57 & 116 & 121 & 600 \\ 103 & 139 & 141 & 230 \\ & 4,962 & & 12,796\end{array}$

$\begin{array}{rrrr}135 & 264 & 63 & 255 \\ 15 & 115 & 10 & 108 \\ 4 & 49 & 11 & 648 \\ 19 & 101 & 4 & 97 \\ 3 & 130 & 20 & 402 \\ 30 & 106 & 18 & 116 \\ 15 & 302 & 6 & 237 \\ 4 & 69 & 1 & 73 \\ 1 & 83 & 3 & 170 \\ 34 & 125 & 162 & 1,200 \\ 1 & 21 & 17 & 195 \\ & 1,365 & & 3,501\end{array}$

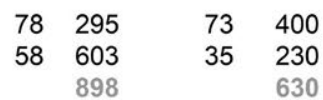

26

$\begin{array}{lll}310 & 4 & 110 \\ 310 & & 110\end{array}$

7,635

17,127

$0.1 \quad 0.512 \quad 10$
Weight Weight

PR

95\% Cl (Random) (Fixed)

1.59 [1.25; 2.03]

$1.59[1.25 ; 2.03]$

$1.59[1.25 ; 2.03]$

$1.80[1.32 ; 2.46]$

$1.51[1.35 ; 1.69]$

$1.12[0.91 ; 1.37]$

$1.49[1.31 ; 1.69]$

$1.24[0.95 ; 1.63]$

$1.76[1.57 ; 1.97]$

$1.71[1.36 ; 2.16]$

$1.33[0.78 ; 2.26]$

$1.43[1.25 ; 1.62]$

$1.86[1.02 ; 3.39]$

$0.99[0.71 ; 1.38]$

$2.57[1.74 ; 3.80]$

$1.28[0.98 ; 1.66]$

$1.46[0.93 ; 2.31]$

$2.44[1.91 ; 3.11]$

$1.21[1.05 ; 1.39]$

$1.50[1.43 ; 1.57]$

$1.49[1.35 ; 1.64]$

$4.4 \% \quad 2.3 \%$

$4.4 \%$

$3.7 \% \quad 0.5 \%$

$5.8 \% \quad 9.6 \%$

$4.9 \% \quad 2.6 \%$

$5.7 \% \quad 12.5 \%$

$4.1 \% \quad 2.5 \%$

$5.8 \% \quad 19.3 \%$

$5.8 \% \quad 14.4 \%$

$4.5 \% \quad 3.9 \%$

$2.1 \% \quad 1.0 \%$

$5.6 \% \quad 2.0 \%$

$1.8 \% \quad 0.6 \%$

$3.5 \% \quad 2.7 \%$

$3.0 \% \quad 1.2 \%$

$4.2 \% \quad 2.8 \%$

$2.5 \% \quad 0.9 \%$

$4.4 \% \quad 2.0 \%$

$5.5 \% \quad 5.4 \%$

-- $84.0 \%$

$73.0 \%$
$1.38[1.24 ; 1.54]$

$2.3 \%$

$2.07 \quad[1.62 ; 2.64]$

1.41 [0.66; 3.00]

$4.81[1.59 ; 14.55]$

$4.56[1.61 ; 12.93]$

$0.46[0.14 ; 1.54]$

$1.82[1.08 ; 3.07]$

$1.96[0.77 ; 4.98]$

$4.23[0.48 ; 36.93]$

$0.68[0.07 ; 6.46]$

2.01 [1.46; 2.78]

$0.55[0.08 ; 3.90]$

$1.93[1.64 ; 2.29]$

$1.93[1.49 ; 2.50]$

$4.4 \% \quad 3.3 \%$

$1.2 \% \quad 0.5 \%$

$0.6 \% \quad 0.1 \%$

$0.7 \% \quad 0.2 \%$

$0.6 \% \quad 0.5 \%$

$2.1 \% \quad 0.9 \%$

$0.9 \% \quad 0.3 \%$

$0.2 \% \quad 0.0 \%$

$0.2 \% \quad 0.1 \%$

$3.6 \% \quad 1.6 \%$

$0.2 \% \quad 0.2 \%$

$-7.7 \%$

$14.8 \%$

$1.45[1.09 ; 1.92] \quad 4.0 \% \quad 3.2 \%$

$0.63[0.43 ; 0.93] \quad 3.0 \% \quad 2.6 \%$

$1.08[0.86 ; 1.35] \quad--5.7 \%$

$0.97[0.43 ; 2.18] \quad 7.0 \%$

$2.31[0.82 ; 6.46]$

$2.31[0.82 ; 6.46]$

$2.31[0.82 ; 6.46]$

$0.7 \% \quad 0.3 \%$

$-\quad 0.3 \%$

$1.52[1.45 ; 1.58]$

$1.52[1.38 ; 1.67]$

$100.0 \%$

FIGURE 3 Subgroup analysis of anti-HEV IgG prevalence stratified by continent

by occupation (Figure 4 and Table 2), the difference in the pooled prevalence of anti-HEV IgG between swine workers and the general population also remained significant. Compared to the general population, the PRs were higher for butchers $(P R=1.75$, $95 \% \mathrm{Cl}: 1.31-2.35)$, swine farmers ( $P R=1.51,95 \% \mathrm{Cl}: 1.32-1.74)$, meat processors $(\mathrm{PR}=1.46,95 \% \mathrm{Cl}: 1.13-1.89)$, veterinarians $(P R=1.36,95 \% \mathrm{Cl}: 1.15-1.61)$ and pork retailers $(P R=1.19,95 \%$ $\mathrm{Cl}$ : 1.09-1.29). The heterogeneity was only low for swine veterinarians $\left(I^{2}=14 \%\right)$ and pork retailers $\left(I^{2}=0 \%\right)$, whereas it was high for all other occupations $\left(I^{2} \geq 81 \%\right)$. 


\section{Study}

occupation $=$ butcher

2005 Zheng Y J

2007 Yan Y S

2009 Zheng R S

2012 Sabrina Monteiro Tosoncin da Silva

2015 Kuan Abdoulaye Traoré

Fixed-effect model

Random-effects model

Heterogeneity: $I^{2}=86 \%, \tau^{2}=0.0821, p<0.01$

occupation $=$ meat processor

2007 Yan Y S

Fixed-effect model

Random-effects model

Heterogeneity: not applicable

occupation $=$ pork retailer

2005 Zheng Y J

2018 WU H Z

Fixed-effect model

Random-effects model

Heterogeneity: $I^{2}=0 \%, \tau^{2}=0, p=0.78$

occupation $=$ swine farmer

1999 Xiang-Jin Meng

2002 MARK R. WITHERS

2002 R. E. Engle

2005 Zheng Y J

2006 BJO" RN OLSEN

2006 Lu Y H

2006 Yingjie Zheng

2007 Liu X G

2007 Nong C S

2007 Yan Y S

2008 Carolina Galiana

2009 G. Masia

2009 Zheng R S

2009 Shao H W

2011 Rosario Vivek

2011 Takako Utsumi

2012 Andi Krumbholz

2013 S. Hinjoy

2013 Jian-Te Lee

2014 Huanbin Liang

2016 C. Caruso

2016 Wu Y

2017 Yuan-Huan Kang

$2017 \mathrm{H}$. LANGE

2018 Love

2018 Wu H Z

Fixed-effect model

Random-effects model

Heterogeneity: $I^{2}=81 \%, \tau^{2}=0.0795, p<0.01$

occupation $=$ swine veterinarian

2002 X. J. Meng

2005 Zheng $Y$ J

2007 Yan Y S

2008 M. BOUWKNEGT

2016 De Sabato L

2017 H. LANGE

Fixed-effect model

Random-effects model

Heterogeneity: $I^{2}=14 \%, \tau^{2}=0.0069, p=0.33$

Fixed-effect model

Random-effects model

Heterogeneity: $I^{2}=79 \%, \tau^{2}=0.0587, p<0.01$
Occupation Control

Positive Total Positive Total

$\begin{array}{rrrr}28 & 35 & 319 & 512 \\ 141 & 396 & 515 & 2,209 \\ 65 & 150 & 94 & 626 \\ 16 & 170 & 4 & 110 \\ 76 & 100 & 43 & 90 \\ & 851 & & 3,547\end{array}$

$42 \quad 123$

$515 \quad 2,209$

2,209

$\begin{array}{llll}158 & 212 & 319 & 512\end{array}$

$\begin{array}{llll}80 & 112 & 141 & 230\end{array}$

324

742

$\begin{array}{llll}11 & 11 & 17 & 31\end{array}$

$\begin{array}{llll}18 & 165 & 3 & 127\end{array}$

$\begin{array}{llll}58 & 603 & 35 & 230\end{array}$

$\begin{array}{llll}30 & 45 & 319 & 512\end{array}$

$\begin{array}{llrl}15 & 115 & 10 & 108\end{array}$

$\begin{array}{llll}31 & 44 & 390 & 619\end{array}$

$\begin{array}{llll}258 & 340 & 213 & 425\end{array}$

$\begin{array}{llll}362 & 785 & 167 & 500\end{array}$

102180

224738

19101

3130

61148

$25 \quad 182$

$23 \quad 34$

212

$30 \quad 106$

$39 \quad 171$

$46 \quad 156$

$55 \quad 114$

$4 \quad 69$

$13 \quad 41$

$57 \quad 116$

$24 \quad 79$

$1 \quad 21$

$23 \quad 27$

4,533

$36 \quad 79$

5152,209

$4 \quad 97$

$20 \quad 402$

$94 \quad 626$

$16 \quad 102$

$21 \quad 100$

242

$18 \quad 116$

$79 \quad 342$

$36 \quad 314$

$74 \quad 193$

$\begin{array}{rr}1 & 73 \\ 175 & 669\end{array}$

175669

121600

1621,200

$17 \quad 195$

141230

10,141

$\begin{array}{rrrr}78 & 295 & 73 & 400 \\ 38 & 48 & 319 & 512 \\ 8 & 33 & 515 & 2,209 \\ 6 & 49 & 27 & 648 \\ 1 & 83 & 3 & 170 \\ 10 & 46 & 162 & 1,200 \\ & 554 & & 5,139\end{array}$

6,385

21,778

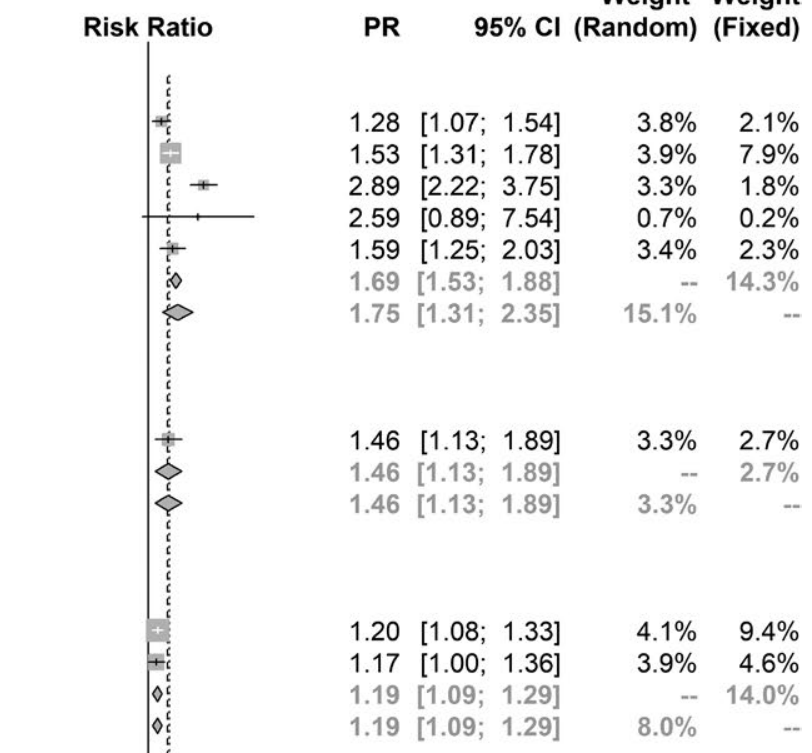

$1.80 \quad[1.32 ; 2.46]$

$4.62[1.39 ; 15.34]$

0.63 [0.43; 0.93$]$

1.07 [0.86; 1.33]

$1.41 \quad[0.66 ; 3.00]$

$1.12[0.91 ; 1.37]$

1.51 [1.35; 1.69]

$1.38 \quad[1.19 ; 1.60]$

$1.24[0.95 ; 1.63]$

$1.30 \quad[1.14 ; 1.49]$

$4.56[1.61 ; 12.93]$

$0.46[0.14 ; 1.54]$

2.74 [2.10; 3.59]

$0.88 \quad[0.49 ; 1.56]$

3.22 [2.06; 5.03]

$3.50[0.55 ; 22.30]$

1.82 [1.08; 3.07]

$0.99 \quad[0.71 ; 1.38]$

$2.57 \quad[1.74 ; 3.80]$

$1.26 \quad[0.97 ; 1.63]$

$4.23[0.48 ; 36.93]$

$1.21 \quad[0.76 ; 1.93]$

2.44 [1.91; 3.11]

2.25 [1.56; 3.24]

$0.55[0.08 ; 3.90]$

1.39 [1.15; 1.68]

$1.44[1.36 ; 1.52]$

$1.51[1.32 ; 1.74]$

$3.0 \% \quad 0.5 \%$

$0.6 \% \quad 0.2 \%$

$2.6 \% \quad 2.5 \%$

$3.6 \% \quad 2.6 \%$

$1.2 \% \quad 0.5 \%$

$3.7 \% \quad 2.6 \%$

$4.1 \% \quad 9.5 \%$

$3.9 \% \quad 10.3 \%$

$3.2 \% \quad 2.5 \%$

$4.0 \% \quad 13.0 \%$

$0.7 \% \quad 0.2 \%$

$0.6 \% \quad 0.5 \%$

$3.3 \% \quad 1.8 \%$

$1.7 \% \quad 1.0 \%$

$2.3 \% \quad 0.5 \%$

$0.3 \% \quad 0.0 \%$

$2.0 \% \quad 0.9 \%$

$2.9 \% \quad 2.6 \%$

$2.6 \% \quad 1.2 \%$

$3.3 \% \quad 2.8 \%$

$0.2 \% \quad 0.0 \%$

$2.2 \% \quad 1.0 \%$

$3.4 \% \quad 2.0 \%$

$2.7 \% \quad 1.0 \%$

$0.2 \% \quad 0.2 \%$

$3.7 \% \quad 1.5 \%$

-- $61.5 \%$

$61.9 \%$

$1.45 \quad[1.09 ; 1.92]$

1.27 [1.08; 1.49]

1.04 [0.57; 1.91]

$2.94 \quad[1.27 ; 6.78]$

$0.68 \quad[0.07 ; 6.46]$

$1.61[0.91 ; 2.84]$

$1.38[1.18 ; 1.61]$

$1.36[1.15 ; 1.61]$

$3.2 \% \quad 3.1 \%$

$3.9 \% \quad 2.7 \%$

$1.6 \% \quad 0.8 \%$

$1.1 \% \quad 0.2 \%$

$0.2 \% \quad 0.1 \%$

$1.8 \% \quad 0.6 \%$

$-7.5 \%$

$11.7 \%$

$1.44[1.38 ; 1.50]$

$1.50[1.36 ; 1.65]$

$--100.0 \%$

$100.0 \%$

FIG URE 4 Subgroup analysis of anti-HEV IgG prevalence stratified by occupation 


\section{4 | DISCUSSION}

Through a meta-analysis of previous studies, we determined that the PR of the pooled prevalence of anti-HEV IgG in swine workers compared to the general population was as high as 1.52 , suggesting swine workers are more likely to be infected with HEV than the general population by $50 \%$. It was confirmed that swine workers have substantially increased prevalence of HEV infection. As the majority of previous studies focusing on anti-HEV antibodies were cross-sectional, we included only cross-sectional studies to conduct the meta-analysis. So far, we are unaware of any prospective study comparing seroconversion between the swine workers and the general population.

In fact, this heterogeneity is the reason that there is conflicting conclusions on the prevalence of HEV infection between diverse swine workers groups or between swine workers and the general population. A previous study even identified swine-related occupations as a protective factor (Engle et al., 2002). To overcome limitations and improve the efficiency of the meta-analysis, we further employed subgroup analyses. We determined that in Asia and Europe, and for specific occupations examined, swine workers had significantly higher pooled prevalence of anti-HEV IgG compared to the general population, suggesting an increased prevalence of HEV infection. For the subgroup analysis by continent, we concluded that there were relatively more Asian and European studies included in the meta-analysis, leading to a more stable estimate, whereas few studies were conducted in Africa, North America or South America. Previous studies have revealed that $\mathrm{HEV}$ is very endemic in eastern and south-eastern Asian countries. In China, HEV prevalence is increasing from a high starting point (Zhu, Liu, Fu, Zhang, \& Mao, 2018). Simultaneously, HEV prevalence has become greater in European countries as confirmed hepatitis E cases have increased over 10-fold between 2005 and 2015 (Aspinall et al., 2017). Additionally, the gap in HEV infection between the swine workers and the general population did not vary between Asia and Europe. Traditionally, it is believed that there are different operational procedures in various regions, especially between industrialized countries (such as those in Europe) and resource-limited countries (such as those in Asia), which may result in a disparity in the prevalence of HEV infection through contact with swine. However, in our study, the included studies conducted in five Asian countries (China, Thailand, Japan, Indonesia and India) and nine European countries (Germany, France, Italy, Norway, Finland, the Netherlands, Sweden, Spain and Moldova) did not differ. Thus, we have evidence that swine workers have substantially increased prevalence of HEV infection, regardless of the socioeconomic circumstances of their country.

For the subgroup analysis by specific swine-related occupation, it was very interesting that all the subgroups gave positive findings in that the swine workers had significantly higher prevalence of anti-HEV IgG compared to the general population. These consistent findings demonstrate that swine workers have substantially increased prevalence of HEV infection, regardless of the specific occupation. Additionally, we found that the gap in HEV infection between the occupation group and the general population did not vary across occupations. Some swine workers such as butchers may be more directly exposed to swine blood, and swine farmers may have more contact with swine faeces, possibly indicating higher prevalence of HEV infection; however, this meta-analysis showed that they had similar PR values compared with meat processors or veterinarians (and the latter is an occupation group who are trained to be careful in self-protection during the examination of animals). In one French study focusing on HEV infection in swine farmers, those who wore gloves had significantly lower prevalence of HEV infection, suggesting self-protection was crucial for the prevention of HEV infection (Chaussade et al., 2013). It is difficult to interpret our findings (the comparison of PR values and $95 \% \mathrm{Cl}$ ) that, among all swine-related occupations, pork retailers had slightly lower prevalence of HEV infection and butchers had the highest prevalence. Pork retailers have only routine contact with pork, while butchers have more direct and frequent contact with animals that may carry HEV and may even be more likely to consume uncooked or undercooked meat (Toyoda et al., 2008). However, the subgroups of meat processors and pork retailers were only examined in one study each, so the results might be not as stable as our estimates for other occupations.

Another way to protect individuals against hepatitis $\mathrm{E}$ infection and disease is through vaccination. A hepatitis $E$ vaccine was licensed in China in 2012, and is currently the only hepatitis E vaccine available in any country (Wu, Chen, Lin, Hao, \& Liang, 2016). Clinical trials in China have found the vaccine efficacious; at 4.5 years, the vaccine had an efficacy of $86.8 \%$ (95\% Cl: 71\%-94\%; Zhang, Shih, \& Xia, 2015). Nonetheless, in a position paper released in 2015 , the World Health Organization did not issue a broad recommendation for routine vaccination, citing a lack of research outside of China and in certain populations ("Hepatitis E vaccine: WHO position paper, May 2015," 2015). Our analysis suggests that swine workers could be a targeted group for vaccination programmes and for future research on the cost-effectiveness of hepatitis E vaccination. Our study examined seropositivity, and not clinical disease, as an outcome, but we can reasonably assume that risk of disease is also higher among swine workers than others in the general population.

In our study, a major limitation is the heterogeneity observed both in the pooled prevalence of anti-HEV IgG and in the subgroup analyses. This heterogeneity may be partly interpreted by different definitions of swine-related occupations and different operational procedures across regions. Another explanation is differing inclusion criteria for swine workers and the general population across studies. However, the consistency between the findings of original pooled analysis and the subgroup analyses could provide concrete evidence validating our hypothesis. It is also possible that other occupations (like hunters) could be a high-risk group, but they were not explicitly considered in this study. Another limitation is that our finding was supported by only the pooled prevalence of anti-HEV IgG.

In summary, swine-related occupations including swine farmers, butchers, meat processors, pork retailers and veterinarians have 
substantially increased the prevalence of past HEV infection compared to non-swine-related population, suggesting swine workers are more likely to be infected with HEV. However, more evidence focusing on current HEV infection is warranted for further confirmation of zoonotic transmission among swine workers.

\section{ACKNOWLEDGEMENTS}

This work was supported by the China National Natural Science Funds (grant number 81370081) and Shanghai Municipal Health and Family Planning Commission (grant number GWTD2015S05). Dr. Wagner received funding through a Fulbright Scholarship.

\section{CONFLICT OF INTEREST}

The authors declare no conflict of interest.

\section{ORCID}

Yihan Lu (iD https://orcid.org/0000-0003-4651-9433

\section{REFERENCES}

Aspinall, E. J., Couturier, E., Faber, M., Said, B., ljaz, S. , \& Tavoschi, L. .... On Behalf of the Country Experts. (2017). Hepatitis E virus infection in Europe: Surveillance and descriptive epidemiology of confirmed cases, 2005 to 2015. Eurosurveillance Weekly, 22(26), pii. 30561. https://doi.org/10.2807/1560-7917.ES.2017.22.26.30561

Bouwknegt, M., Engel, B., Herremans, M. M., Widdowson, M. A., Worm, H. C., Koopmans, M. P., ... Van Der Poel, W. H. (2008). Bayesian estimation of hepatitis $\mathrm{E}$ virus seroprevalence for populations with different exposure levels to swine in The Netherlands. Epidemiology and Infection, 136(4), 567-576. https://doi.org/10.1017/ S0950268807008941

Caruso, C. , Peletto, S., Rosamilia, A., Modesto, P. , Chiavacci, L. , Sona, B. , ... Masoero, L. (2017). Hepatitis E Virus: A crosssectional serological and virological study in pigs and humans at zoonotic risk within a high-density pig farming area. Transboundary and Emerging Diseases, 64(5), 1443-1453. https://doi.org/10.1111/ tbed.12533

Chaussade, H., Rigaud, E., Allix, A., Carpentier, A., Touze, A., Delzescaux, D., ... Coursaget, P. (2013). Hepatitis E virus seroprevalence and risk factors for individuals in working contact with animals. Journal of Clinical Virology, 58(3), 504-508. https://doi.org/10.1016/j. jcv.2013.08.030

De Sabato, L., Di Bartolo, I., Montomoli, E., Trombetta, C., Ruggeri, F. M., \& Ostanello, F. (2017). Retrospective study evaluating seroprevalence of Hepatitis $E$ virus in blood donors and in swine veterinarians in Italy (2004). Zoonoses Public Health, 64(4), 308-312. https://doi. org/10.1111/zph.12332

De Schryver, A., De Schrijver, K., Francois, G., Hambach, R., van Sprundel, M., Tabibi, R., \& Colosio, C. (2015). Hepatitis E virus infection: An emerging occupational risk? Occupational Medicine (London), 65(8), 667-672. https://doi.org/10.1093/occmed/kqv154

Doceul, V., Bagdassarian, E., Demange, A., \& Pavio, N. (2016). Zoonotic Hepatitis $\mathrm{E}$ virus: Classification, animal reservoirs and transmission routes. Viruses, 8(10), pii:E270. https://doi.org/10.3390/v8100270

Drobeniuc, J., Favorov, M. O., Shapiro, C. N., Bell, B. P., Mast, E. E., Dadu, A., ... Margolis, H. S. (2001). Hepatitis E virus antibody prevalence among persons who work with swine. Journal of Infectious Diseases, 184(12), 1594-1597. https://doi.org/10.1086/324566

Engle, R. E., Yu, C., Emerson, S. U., Meng, X. J., \& Purcell, R. H. (2002). Hepatitis $E$ virus (HEV) capsid antigens derived from viruses of human and swine origin are equally efficient for detecting anti-HEV by enzyme immunoassay. Journal of Clinical Microbiology, 40(12), 4576-4580. https://doi.org/10.1128/JCM.40.12.4576-4580.2002

Galiana, C., Fernandez-Barredo, S., Garcia, A., Gomez, M. T., \& Perez-Gracia, M. T. (2008). Occupational exposure to Hepatitis E virus (HEV) in swine workers. American Journal of Tropical Medicine and Hygiene, 78(6), 1012-1015. https://doi.org/10.4269/ ajtmh.2008.78.1012

Hepatitis E vaccine: WHO position paper, May 2015. (2015). Weekly Epidemiological Record, 90(18), 185-200.

Hinjoy, S., Nelson, K. E., Gibbons, R. V., Jarman, R. G., Mongkolsirichaikul, D., Smithsuwan, P., ... Patchanee, P. (2013). A cross-sectional study of hepatitis $\mathrm{E}$ virus infection in healthy people directly exposed and unexposed to pigs in a rural community in northern Thailand. Zoonoses Public Health, 60(8), 555-562. https://doi.org/10.1111/ zph.12030

Hongwei, S. (2009). Epidemiological investigation of Hepatitis E Virus in Changchun. Journal of Shandong Education Institute, 24(04), 93-95.

Jiang, X., Zheng, R., \& Shijuan, Y. (2009). Seroepidemiological investigation on virus hepatitis E among different crowds in Mudanjiang City. Chinese Journal of School Doctor, 25(12), 935-936.

Kang, Y. H., Cong, W., Zhang, X. Y., Wang, C. F., Shan, X. F., \& Qian, A. D. (2017). Hepatitis $E$ virus seroprevalence among farmers, veterinarians and control subjects in Jilin province, Shandong province and Inner Mongolia Autonomous Region, China. Journal of Medical Virology, 89(5), 872-877. https://doi.org/10.1002/jmv.24693

Krumbholz, A., Joel, S., Dremsek, P., Neubert, A., Johne, R., Durrwald, R., ... Zell, R. (2014). Seroprevalence of Hepatitis E virus (HEV) in humans living in high pig density areas of Germany. Medical Microbiology and Immunology, 203(4), 273-282. https://doi.org/10.1007/ s00430-014-0336-3

Krumbholz, A., Mohn, U., Lange, J., Motz, M., Wenzel, J. J., Jilg, W., ... Zell, R. (2012). Prevalence of Hepatitis E virus-specific antibodies in humans with occupational exposure to pigs. Medical Microbiology and Immunology, 201(2), 239-244. https://doi.org/10.1007/ s00430-011-0210-5

Lange, H., Overbo, J., Borgen, K., Dudman, S., Hoddevik, G., Urdahl, A. M., ... Sjurseth, S. K. (2017). Hepatitis E in Norway: Seroprevalence in humans and swine. Epidemiology and Infection, 145(1), 181-186. https://doi.org/10.1017/S0950268816002144

Lee, J. T. , Shao, P. L., Chang, L. Y., Xia, N. S., Chen, P. J. , Lu, C. Y. , \& Huang, L. M. (2013). Seroprevalence of Hepatitis E virus infection among swine farmers and the general population in rural Taiwan. PLoS One, 8(6), e67180. https://doi.org/10.1371/journal. pone. 0067180

Liang, H., Su, S., Deng, S., Gu, H., Ji, F., Wang, L., ... Zhang, G. (2014). The prevalence of hepatitis $E$ virus infections among swine, swine farmers and the general population in Guangdong Province. China. Plos One, 9(2), e88106. https://doi.org/10.1371/journal. pone.0088106

Liu, P., Li, L., Wang, L., Bu, Q., Fu, H., Han, J., ... Zhuang, H. (2012). Phylogenetic analysis of 626 hepatitis E virus (HEV) isolates from humans and animals in China (1986-2011) showing genotype diversity and zoonotic transmission. Infection, Genetics and Evolution, 12(2), 428-434. https://doi.org/10.1016/j.meegid.2012.01.017

Liu, X. G., Li, X. J., Chen, P., Song, A. J., Luo, J., Fan, J. P., \& Jing, L. (2007). Investigation of Infection with Hepatitis $\mathrm{E}$ virus among pigs and different personnels in Hubei. Chinese Journal of Frontier Health and Quarantine, 30, 273-277.

Love, A., Bjornsdottir, T. B., Olafsson, S., \& Bjornsson, E. S. (2018). Low prevalence of hepatitis $\mathrm{E}$ in Iceland: A seroepidemiological study. 
Scandinavian Journal of Gastroenterology, 53(3), 293-296. https://doi. org/10.1080/00365521.2017.1420218

Lu, Y., Song, J., Jiang, Q., Wang, F., Xiaolian, D., Lianhua, Z., \& Jiangliang, F. (2006). Prevalence of IgG-class antibodies to hepatitis $E$ virus in a rural population in Zhejiang Province. Fudan University Journal of Medical Sciences, 3, 357-362.

Masia, G., Orru, G., Liciardi, M., Desogus, G., Coppola, R. C., Murru, V., ... Orru, G. (2009). Evidence of hepatitis E virus (HEV) infection in human and pigs in Sardinia, Italy. Journal of Preventive Medicine and Hygiene, 50(4), 227-231.

Meng, X. J., Dea, S., Engle, R. E., Friendship, R., Lyoo, Y. S., Sirinarumitr, T., ... Emerson, S. U. (1999). Prevalence of antibodies to the hepatitis $E$ virus in pigs from countries where hepatitis $E$ is common or is rare in the human population. Journal of Medical Virology, 59(3), 297-302. https://doi.org/10.1002/ (SICI)1096-9071(199911)59:3<297:AID-JMV6>3.0.CO;2-3

Meng, X. J., Wiseman, B., Elvinger, F., Guenette, D. K., Toth, T. E., Engle, R. E., ... Purcell, R. H. (2002). Prevalence of antibodies to hepatitis $E$ virus in veterinarians working with swine and in normal blood donors in the United States and other countries. Journal of Clinical Microbiology, 40(1), 117-122. https://doi.org/10.1128/ JCM.40.1.117-122.2002

Mushahwar, I. K. (2008). Hepatitis E virus: Molecular virology, clinical features, diagnosis, transmission, epidemiology, and prevention. Journal of Medical Virology, 80(4), 646-658. https://doi.org/10.1002/ jmv.21116

Nair, V. P. , Anang, S., Subramani, C., Madhvi, A., Bakshi, K. , Srivastava, A. , ... Surjit, M. (2016). Endoplasmic reticulum stress induced synthesis of a novel viral factor mediates efficient replication of genotype-1 Hepatitis E virus. PLoS Pathogens, 12(4), e1005521. https://doi.org/10.1371/journal.ppat.1005521

Nan, Y., \& Zhang, Y. J. (2016). Molecular biology and infection of Hepatitis E virus. Frontiers in Microbiology, 7, 1419. https://doi.org/10.3389/ fmicb.2016.01419

Nong, C., Li, Y., \& Yi, N. (2007). Investigation of HEV infection among rural Zhuang ethnic population. Journal of Applied Preventive Medicine, 4, 234-235.

Olsen, B., Axelsson-Olsson, D., Thelin, A., \& Weiland, O. (2006). Unexpected high prevalence of IgG-antibodies to hepatitis $E$ virus in Swedish pig farmers and controls. Scandinavian Journal of Infectious Diseases, 38(1), 55-58. https://doi. org/10.1080/00365540500321470

Salines, M., Andraud, M., \& Rose, N. (2017). From the epidemiology of hepatitis $E$ virus (HEV) within the swine reservoir to public health risk mitigation strategies: A comprehensive review. Veterinary Research, 48(1), 31. https://doi.org/10.1186/s13567-017-0436-3

Silva, S. M., Oliveira, J. M., Vitral, C. L., Vieira Kde, A., Pinto, M. A., \& Souto, F. J. (2012). Prevalence of hepatitis E virus antibodies in individuals exposed to swine in Mato Grosso, Brazil. Memórias do Instituto Oswaldo Cruz, 107(3), 338-341. https://doi.org/10.1590/ S0074-02762012000300007

Smith, D. B., Simmonds, P., Jameel, S., Emerson, S. U., Harrison, T. J., Meng, X.-J., ... Purdy, M. A. (2014). Consensus proposals for classification of the family Hepeviridae. Journal of General Virology, 95(Pt 10), 2223-2232. https://doi.org/10.1099/vir.0.068429-0

Toyoda, K., Furusyo, N., Takeoka, H., Murata, M., Sawayama, Y., \& Hayashi, J. (2008). Epidemiological study of hepatitis E virus infection in the general population of Okinawa, Kyushu, Japan. Journal of Gastroenterology and Hepatology, 23(12), 1885-1890. https://doi. org/10.1111/j.1440-1746.2008.05568.x
Traore, K. A., Ouoba, J. B., Huot, N., Rogee, S., Dumarest, M., Traore, A. S., ... Roques, P. (2015). Hepatitis $E$ virus exposure is increased in pork butchers from Burkina Faso. American Journal of Tropical Medicine and Hygiene, 93(6), 1356-1359. https://doi.org/10.4269/ajtmh.15-0321

Utsumi, T., Hayashi, Y., Lusida, M. I., Amin, M., Soetjipto, H., Hendra, A., ... Hotta, H. (2011). Prevalence of Hepatitis E virus among swine and humans in two different ethnic communities in Indonesia. Archives of Virology, 156(4), 689-693. https://doi.org/10.1007/ s00705-010-0883-x

Vivek, R., \& Kang, G. (2011). Hepatitis E virus infections in swine and swine handlers in Vellore, Southern India. American Journal of Tropical Medicine and Hygiene, 84(4), 647-649. https://doi.org/10.4269/ ajtmh.2011.10-0456

Wu, H., Liao, Z., Wang, P., Lou, Y., \& Wenzhong, H. (2018). An survey on the status of hepatitis $E$ virus infection among different population groups in rural areas of central Zhejiang province. Chinese Rural Health Service Administration, 38(01), 43-46.

Wu, X., Chen, P., Lin, H., Hao, X., \& Liang, Z. (2016). Hepatitis E virus: Current epidemiology and vaccine. Human Vaccines \& Immunotherapeutics, 12(10), 2603-2610. https://doi.org/10.1080/2 1645515.2016.1184806

Wu, Y., Xie, Y., Chen, M., Yan, K., Liu, A., \& Lu, H. (2016). Investigation and analysis of HEV infection among general population in Zhenhai, Ningbo. Modern Practical Medicine, 28(03), 330-331.

Yan, Y. S., Wang, H. R., Wang, L. L., Chen, L., Xiao, J. X., He, S., \& Lin, Q. (2007). A sero-epidemiology study on hepatitis $E$ virus infection in Fujian province. Zhonghua Liu Xing Bing Xue Za Zhi, 28(2), 105-108.

Yu, Y., Sun, J., Liu, M., Xia, L., Zhao, C., Harrison, T. J., \& Wang, Y. (2009). Seroepidemiology and genetic characterization of hepatitis $E$ virus in the northeast of China. Infection, Genetics and Evolution, 9(4), 554561. https://doi.org/10.1016/j.meegid.2009.02.008

Zhang, J., Shih, J. W., \& Xia, N. S. (2015). Long-term efficacy of a hepatitis E vaccine. New England Journal of Medicine, 372(23), 2265-2266. https://doi.org/10.1056/NEJMc1504302

Zheng, Y., Ge, S., Zhang, J., Guo, Q., Ng, M. H., Wang, F., ... Jiang, Q. (2006). Swine as a principal reservoir of hepatitis $E$ virus that infects humans in Eastern China. Journal of Infectious Diseases, 193(12), 1643-1649. https://doi.org/10.1086/504293

Zhu, B., Liu, J., Fu, Y., Zhang, B., \& Mao, Y. (2018). Spatio-temporal epidemiology of viral hepatitis in China (2003-2015): Implications for prevention and control policies. International Journal of Environmental Research and Public Health, 15(4), 2003-2015. https://doi. org/10.3390/ijerph15040661

\section{SUPPORTING INFORMATION}

Additional supporting information may be found online in the Supporting Information section at the end of the article.

How to cite this article: Huang $X$, Huang $Y$, Wagner $A L$, Chen X, Lu Y. Hepatitis E virus infection in swine workers: A meta-analysis. Zoonoses Public Health. 2019;66:155-163. https://doi.org/10.1111/zph.12548 